\title{
Observations of atmosphere-biosphere exchange of total and speciated peroxynitrates: nitrogen fluxes and biogenic sources of peroxynitrates
}

\author{
K.-E. Min ${ }^{1,}$, S. E. Pusede ${ }^{2}$, E. C. Browne ${ }^{2}$, B. W. LaFranchi ${ }^{2, * *}$, P. J. Wooldridge ${ }^{2}$, G. M. Wolfe ${ }^{3, * * *}$, S. A. Harrold ${ }^{3}$, \\ J. A. Thornton ${ }^{3}$, and R. C. Cohen ${ }^{1,2}$ \\ ${ }^{1}$ University of California at Berkeley, Department of Earth and Planetary Science, CA, USA \\ ${ }^{2}$ University of California at Berkeley, Department of Chemistry, CA, USA \\ ${ }^{3}$ University of Washington, Department of Atmospheric Sciences, Seattle, WA, USA \\ *now at: NOAA Earth System Research Laboratory and Cooperative Institute for Research in Environmental Sciences, \\ University of Colorado, Boulder, CO, USA \\ ** now at: Lawrence Livermore National Lab, Center for Accelerator Mass Spectrometry (CAMS), Livermore, CA, USA \\ *** now at: Department of Chemistry, University of Wisconsin, Madison, USA
}

Correspondence to: R. C. Cohen (rccohen@berkeley.edu)

Received: 1 February 2012 - Published in Atmos. Chem. Phys. Discuss.: 28 February 2012

Revised: 2 October 2012 - Accepted: 11 October 2012 - Published: 29 October 2012

\begin{abstract}
Peroxynitrates are responsible for global scale transport of reactive nitrogen. Recent laboratory observations suggest that they may also play an important role in delivery of nutrients to plant canopies. We measured eddy covariance fluxes of total peroxynitrates ( $\Sigma P N s)$ and three individual peroxynitrates (APNs $\equiv \mathrm{PAN}+\mathrm{PPN}+\mathrm{MPAN}$ ) over a ponderosa pine forest during the Biosphere Effects on AeRosols and Photochemistry EXperiment 2009 (BEARPEX 2009). Concentrations of these species were also measured at multiple heights above and within the canopy. While the abovecanopy daytime concentrations are nearly identical for $\Sigma$ PNs and APNs, we observed the downward flux of $\Sigma$ PNs to be $30-60 \%$ slower than the flux of APNs. The vertical concentration gradients of $\Sigma$ PNs and APNs vary with time of day and exhibit different temperature dependencies. These differences can be explained by the production of peroxynitrates other than PAN, PPN, and MPAN within the canopy (presumably as a consequence of biogenic VOC emissions) and upward fluxes of these PN species. The impact of this implied peroxynitrate flux on the interpretation of $\mathrm{NO}_{\mathrm{x}}$ fluxes and ecosystem $\mathrm{N}$ exchange is discussed.
\end{abstract}

\section{Introduction}

Peroxynitrates, PNs $\left(\mathrm{RO}_{2} \mathrm{NO}_{2} \equiv\right.$ acyl peroxynitrates + nonacyl peroxynitrates) represent $25 \%$ or more of the reactive nitrogen in the troposphere. PNs are thermally unstable at characteristic surface temperatures but have very long lifetimes (days to weeks) aloft. As a result, peroxynitrates are temporary reservoirs of $\mathrm{NO}_{\mathrm{x}}\left(\equiv \mathrm{NO}+\mathrm{NO}_{2}\right)$ affecting regional and global tropospheric ozone formation (Hudman et al., 2004; Zhang et al., 2008; Parrish et al., 2009; Fiore et al., 2011) by sequestering $\mathrm{NO}_{\mathrm{x}}$ at the source and then releasing it in downwind rural and remote regions. PNs may also have a significant influence on climate via their effects on available nitrogen and thus ecosystem productivity (Bytnerowicz and Fenn, 1996; Goulding et al., 1998; Sparks et al., 2003; Teklemariam and Sparks, 2004; Sparks, 2009) and via their phytotoxicity and thus ecosystem health (Okano et al., 1990; Goulding et al., 1998). Recent research has brought attention to new mechanisms by which peroxynitrates might participate in linking the atmospheric and biospheric $\mathrm{N}$ cycles (Townsend et al., 1996; Holland et al., 1997; Teklemariam and Sparks, 2004; Sparks, 2009).

Measurements at the leaf scale (Okano et al., 1990; Sparks et al., 2003) and studies assuming assume flux-gradient similarity (Doskey et al., 2004) have suggested that the direct 
uptake of PAN $\left(\mathrm{CH}_{3} \mathrm{C}(\mathrm{O}) \mathrm{OONO}_{2}\right)$ by plants is fast and controlled by stomatal processes. Early work focused only on PAN's phototoxicity (Taylor, 1969; Ordin et al., 1971; Okano et al., 1990; Oka et al., 2004) assuming exclusively negative impacts due to foliar uptake on ecosystem health (Bytnerowicz and Fenn, 1996). In contrast, Sparks (2009) pointed out that direct foliar uptake of atmospheric reactive nitrogen to biota could be a major source of global $\mathrm{N}$ input to ecosystems. Teklemariam and Sparks (2004) estimated as much as $20 \%$ of regional dry deposition of $\mathrm{N}$ occurs via foliar uptake of PAN and that this addition could serve to enhance productivity (Teklemariam and Sparks, 2004). To the extent that stomatal processes dominate, PN deposition will occur according to spatial and temporal patterns that are different from $\mathrm{HNO}_{3}$, as $\mathrm{HNO}_{3}$ deposition is thought to be controlled only by turbulent transport to surfaces and, as a result, PN deposition could be an even larger percentage of the total in some locations.

New measurement techniques have enabled the use of eddy-covariance methods (Turnipseed et al., 2006; Farmer et al., 2006; Wolfe et al., 2009) providing more detailed observations of the rate of exchange of PNs between the atmosphere and biosphere. Analyses of these recent experiments indicate that a complex interplay of chemistry and turbulent exchange occurs, making it difficult to isolate direct foliar uptake, but providing information about a variety of other chemical and micrometeorological processes. All of these new experiments suggest that our current understanding of the mechanisms governing ecosystem exchange of PNs is poor. Turnipseed et al. (2006) found the deposition of PAN to be four times faster than estimated based on a resistance analogy to $\mathrm{H}_{2} \mathrm{O}$. Farmer et al. (2006) found that the net flux of total PNs ( $\Sigma$ PNs) were upward - contrary to all prior expectations. Wolfe et al. (2009) observed downward fluxes of speciated PNs, at the same site as Farmer et al. (2006) but three years later, and observed that three individual PNs each deposits at a different rate (Wolfe et al., 2009).

Building on the prior experiments by Farmer et al. (2006) and Wolfe et al. (2009), we measured fluxes and gradients of total and speciated peroxynitrates ( $\Sigma$ PNs and APNs, respectively) above a ponderosa pine forest during the Biosphere Effects on AeRosols and Photochemistry EXperiment 2009 (BEARPEX 2009). Our goal was to develop an observational database that could provide insights into the chemistry and ecosystem biology that affect forest-atmosphere PN exchange. These measurements provide evidence for processes that result in both the upward and downward exchange of PNs and indicate that the net is a subtle balance between these opposing processes. They also provide evidence for PN formation from one or more unidentified VOC, within the forest canopy. These molecules, hereafter denoted XPNs, are then transported to the atmosphere above.

\section{Research site and instrumentation}

The observations used in this work were collected at a research site located on the western slope of the Sierra Nevada Mountains from 15 June to 31 July in 2009 as a part of the BEARPEX field campaign. An overview of this experiment is found in Cohen et al. (in prep.) and in the articles included in this special issue of ACP. The BEARPEX research site was located $75 \mathrm{~km}$ downwind of Sacramento, California at a managed ponderosa pine plantation owned by Sierra Pacific Industries and near the University of California at Berkeley Blodgett Forest Research Station $\left(38^{\circ} 53^{\prime} 42.9^{\prime \prime} \mathrm{N}, 120^{\circ} 3757.9^{\prime \prime} \mathrm{W}\right.$, and $\left.1315 \mathrm{~m}\right)$. In the summer (May to September), wind patterns at the site are controlled by the topography and are characterized by southwesterlies $\left(210-240^{\circ}\right)$ during daytime and northeasterlies $\left(30^{\circ}\right)$ at night. More detailed descriptions of the local and regional meteorology are available elsewhere (Dillon et al., 2002; Cahill et al., 2006; Choi et al., 2011; Bianco et al., 2011). The forest at this site is dominantly Pinus ponderosa L., planted in 1990, with some Douglas fir, white fir, and incense cedar. The canopy understory is largely mountain whitethorn (Ceanothus cordulatus) and manzanita (Arcostaphylos spp.) shrubbery (up to $2 \mathrm{~m}$ in height). The average canopy heights in 2004, 2006, and 2009 were $5.1 \mathrm{~m}$, $7.9 \mathrm{~m}$, and $8.8 \mathrm{~m}$, respectively and the leaf area indices (LAI) determined to be $2.1 \mathrm{~m}^{2} \mathrm{~m}^{-2}, 3.2 \mathrm{~m}^{2} \mathrm{~m}^{-2}$ and $3.7 \mathrm{~m}^{2} \mathrm{~m}^{-2}$ by onsite surveys conducted on 8 April 2004, 4 October 2006, and 17 July 2009.

At the BEARPEX site, there were two walkup towers separated by a distance of $10 \mathrm{~m}$, a $15 \mathrm{~m}$ tower (south tower) and an $18 \mathrm{~m}$ tower (north tower). On the south tower, meteorological parameters, including temperature, relative humidity, wind speed, net radiation, photosynthetically active radiation (PAR), and chemical species (water vapor, $\mathrm{CO}_{2}$, and $\left.\mathrm{O}_{3}\right)$ were monitored at 5 heights $(1.2,3.0,4.9,8.75$, and $12.5 \mathrm{~m}$ ). Fluxes of water vapor, $\mathrm{CO}_{2}$ and $\mathrm{O}_{3}$ were also measured at $12.5 \mathrm{~m}$. On the north tower, vertical gradients of meteorological parameters were also monitored, including temperature, relative humidity and wind speed. Chemical species observed on the north tower, or on an adjacent height adjustable lift, included $\mathrm{NO}, \mathrm{NO}_{2}, \mathrm{HONO}$, $\Sigma$ PNs and PAN, PPN $\left(\mathrm{CH}_{3} \mathrm{CH}_{2} \mathrm{C}(\mathrm{O}) \mathrm{OONO}_{2}\right)$, MPAN $\left(\mathrm{CH}_{3} \mathrm{C}\left(\mathrm{CH}_{2}\right) \mathrm{C}(\mathrm{O}) \mathrm{OONO}_{2}\right)$, total alkyl nitrates ( $\left.\Sigma \mathrm{ANs}\right)$ and several speciated $\mathrm{ANs}, \mathrm{HNO}_{3}, \mathrm{OH}, \mathrm{HO}_{2}$, total $\mathrm{OH}$ reactivity, $\mathrm{O}_{3}$, numerous BVOCs, formaldehyde, glyoxal, methylglyoxal, and several organic peroxides. Aerosol chemical and physical properties were also measured. While some measurements were made only at the $17.5 \mathrm{~m}$ height many others were also collected at one or more of the following heights $0.5,2.4,5.4,9.2$ and $13.3 \mathrm{~m}$. For simplicity, we refer to these measurement heights as $0.5,2$, $5,9,13$ and $18 \mathrm{~m}$ in the remainder of this text. Needle temperature, soil moisture, soil temperature, and soil heat 
Table 1. Vertical placement of measurements used in this study on north tower.

\begin{tabular}{llll}
\hline Height[m] & Met Data & $\begin{array}{l}\mathrm{NO}_{\mathrm{yi}} \\
(\mathrm{TD}-\mathrm{LIF})\end{array}$ & $\begin{array}{l}\text { APNs } \\
\text { (CIMS) }\end{array}$ \\
\hline $18(17.5)$ & $T, \mathrm{RH}$ & $\mathrm{NO}_{2}, \Sigma \mathrm{PNs}, \Sigma \mathrm{ANs}, \mathrm{HNO}_{3}$ & PAN, PPN, MPAN \\
$13(13.3)$ & $T, \mathrm{RH}$ & - & PAN, PPN, MPAN \\
$9(8.8)$ & $T, \mathrm{RH}$ & $\mathrm{NO}_{2}, \Sigma$ PNs, $\Sigma$ ANs & PAN, PPN, MPAN \\
$5(5.4)$ & $T, \mathrm{RH}$ & $\mathrm{NO}_{2}, \Sigma$ PNs, $\Sigma$ ANs & PAN, PPN, MPAN \\
$2(2.4)$ & $T, \mathrm{RH}$ & - & PAN, PPN, MPAN \\
$0.5(0.5)$ & $\mathrm{N} / \mathrm{A}$ & $\mathrm{NO}_{2}, \Sigma$ PNs, $\Sigma$ ANs & PAN, PPN, MPAN \\
\hline
\end{tabular}

flux were also monitored. Observations are available at http://www.cchem.berkeley.edu/rccgrp.

In this study we focus on the measurements of $\Sigma$ PNs, PAN, PPN, MPAN, and meteorological parameters summarized in Table 1. The inlets for the flux measurements used in this study shared a single sonic anemometer (Campbell Scientific CSAT3 3-D Sonic Anemometer) located 0.2m horizontal and $<0.01 \mathrm{~m}$ vertical displacement from TD-CIMs inlet and with the same $0.2 \mathrm{~m}$ horizontal and $0.03 \mathrm{~m}$ vertical displacement from the TD-LIF inlet.

Thermal dissociation - laser induced fluorescence (TDLIF) was used for the measurement of NOyi $\left(\mathrm{NO}_{2}, \Sigma \mathrm{PNs}\right.$, $\Sigma$ ANs and $\mathrm{HNO}_{3}$ ). Briefly, thermal dissociation of each of these classes of higher oxides converts them to $\mathrm{NO}_{2}$ and a companion radical at $180^{\circ} \mathrm{C}$ for $\Sigma \mathrm{PNs}, 350^{\circ} \mathrm{C}$ for $\Sigma \mathrm{ANs}$, and $600{ }^{\circ} \mathrm{C}$ for $\mathrm{HNO}_{3}$ (Day et al., 2002). $\mathrm{NO}_{2}$ is then detected by LIF (Thornton et al., 2000). Two autonomous homebuilt TD-LIF systems were deployed at BEARPEX 2009 for the simultaneous measurement of fluxes and gradients. In both systems, excitation of a $585 \mathrm{~nm}$ rovibronic feature of $\mathrm{NO}_{2}$ was provided by a frequency doubled Nd:YAG laser (Spectra Physics, average power of $2 \mathrm{~W}$ at $532 \mathrm{~nm}, 30 \mathrm{~ns}$ pulse length) pumping a custom-built tuneable dye laser operating at $8 \mathrm{kHz}$. The fluorescence signal long of $700 \mathrm{~nm}$ was imaged onto a red sensitive photocathode (Hamamatsu H7421-50) and gated photon counting techniques (Stanford Research Systems, SRS 400) were employed to discriminate against prompt background signals. Laboratory measurements and in-field comparisons showed the two TD-LIF instruments to have calibrations that were identical to within $3 \%( \pm 2.5 \%$, $1 \sigma, R^{2}=0.92$ ).

The APNs, PAN, PPN, and MPAN, were measured by thermal dissociation - chemical ionization mass spectrometry (TD-CIMS) with an iodide reagent ion source. A detailed instrument description, including a discussion of the specific configuration for the BEARPEX measurements, is presented in Wolfe et al. (2009). Briefly, thermally dissociated acyl peroxy (PA) radicals are reacted with iodide ion to form carboxylate anions, which are detected using a quadrupole mass spectrometer. Masses corresponding to PAN $(\mathrm{m} / \mathrm{z}=58.7)$, $\operatorname{PPN}(m / z=72.7)$ and MPAN $(m / z=84.7)$ were detected at $3.3 \mathrm{~Hz}$ time resolution.

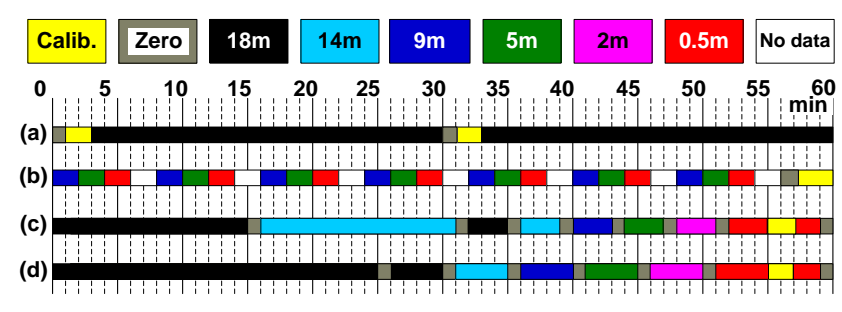

Fig. 1. Colors represent difference measurement heights of $18 \mathrm{~m}$ (black), $14 \mathrm{~m}$ (light blue), $9 \mathrm{~m}$ (blue), $5 \mathrm{~m}$ (green), $2 \mathrm{~m}$ (magenta) and $0.5 \mathrm{~m}$ (red). Yellow and shaded periods are calibration and zero cycles and white periods represent no data collected at that time. (a) Flux measurement of $\Sigma$ PNs, (b) vertical gradient measurements from $\Sigma$ PNs, (c) APNs measurement over the flux-divergence mode, (d) same as (c) but over the normal mode.

The sampling inlets for $\Sigma$ PNs, as well as $\mathrm{NO}_{2}, \Sigma$ ANs, and $\mathrm{HNO}_{3}$, and APNs were co-located. The time sequence of the observations is shown in Fig. 1. Fluxes from the TDLIF system measurements were measured at $18 \mathrm{~m}$ during the first $30 \mathrm{~min}$ from the $3 \mathrm{rd}$ min to the 30 th $\mathrm{min}$ and the last $30 \mathrm{~min}$ from the $33 \mathrm{rd} \mathrm{min}$ to the 60th min each hour (Fig. 1a). $\mathrm{NO}_{\mathrm{yi}}$ measurements at the other heights were collected by switching between the 9,5 , and $0.5 \mathrm{~m}$ heights sampling at each height for 2 min (Fig. 1. row b).

TD-CIMS measurements had two different modes, a flux divergence mode (Fig. 1. row c) and a normal mode (Fig. 1, row d). During the flux divergence mode (day of year 165183), concentrations at $18 \mathrm{~m}$ and $13 \mathrm{~m}$ were measured for $15 \mathrm{~min}$ each, alternating between either the first or last $30 \mathrm{~min}$ of the hour and measuring concentrations at 18, 13, 9, 5, 2 and $0.5 \mathrm{~m}$ for $3 \mathrm{~min}$ each for the other $30 \mathrm{~min}$ of each hour. After day 183, fluxes were only monitored at $18 \mathrm{~m}$, from the 0th min to the 25th min (Fig. 1. row d).

The data used in this study are from days after 176 when the TD-CIMS measurements were more reliable. Data affected by exhaust plumes from a nearby propane power generator (mostly at night) and the occasional wafts of car exhaust were removed prior to analysis. These spikes are defined as variations in the $\Sigma \mathrm{PN}$ or APN concentration in excess of 3 times the standard deviation of the 10-min running 


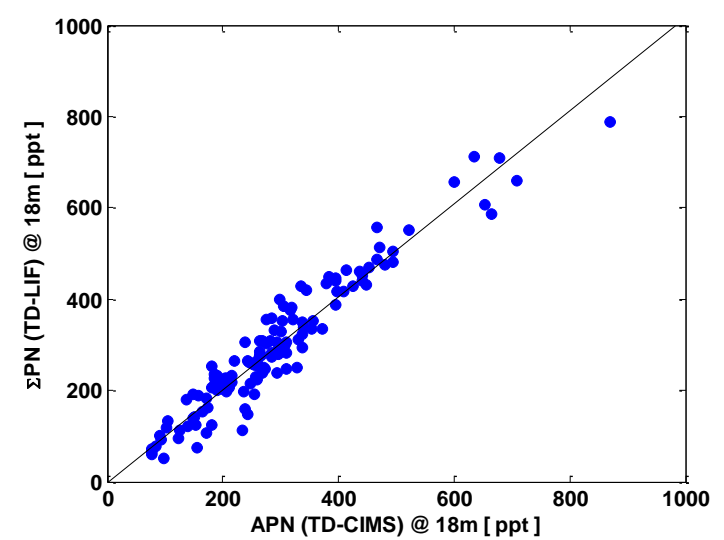

Fig. 2. Comparison of TD-LIF $\Sigma$ PNs and TD-CIMS APNs measurements from 09:00 to 18:00 PST (blue circles). The slope of the line fitted line (black) is 1.02 with the intercept fixed at 0 $\left(R^{2}=0.92\right)$.

mean. A few remaining spikes were identified through correlations with $\mathrm{CO}, \mathrm{NO}$, and $\mathrm{NO}_{2}$ and removed by hand.

To ensure the time synchronous comparison of measurements by multiple instruments, 30-min data resolution was calculated as the averaged value of the 0th to the 30th min and from the 30th to the 60th min at each height and is representative of the first and the last halves of each hour. For the vertical gradients in Fig. 7, 1-h data resolution was achieved by averaging from the 0th to 60th min.

The comparison of daytime (09:00-18:00) measurements of $\Sigma$ PNs and APNs at $18 \mathrm{~m}$ is shown in Fig. 2. The measurements are identical to within $5 \%$, and a least-square linear fit, forcing the intercept through zero, yields a slope of $1.02 \pm 0.026$ with $R^{2}=0.92$. If we allow the intercept to vary we find a slope of $1.047 \pm 0.038$ and an 8ppt intercept, however there is no improvement in the $R^{2}$. The quality of the comparison between $\Sigma \mathrm{PN}$ and APN measurements is consistent with previous studies (Wooldridge et al., 2010). It should be noted that attempts to cross-calibrate with a pure PAN source in the field were unsuccessful and that each instrument was calibrated independently with respect to a different reference gas.

\section{EC flux calculation}

Detailed procedures for flux calculations are described elsewhere for $\Sigma$ PNs (Farmer et al., 2006) and APNs (Wolfe et al., 2009). Briefly, 3-D winds are rotated using the 2-step natural wind coordinate rotation, and concentrations data are de-spiked and de-trended using a 10-min running mean. The time lag between wind and concentration signals is calculated by shifting the concentration time series relative to the winds and optimizing the covariance calculated by Eq. (1). Since this lag should depend only on the physical setup (particularly the inlet residence time), a single average lag was applied to all data. The eddy-covariance flux, $F_{\mathrm{c}}$, of species $c$ is calculated using the covariance between the vertical wind speed, $w$, and the mixing ratio of $c$ by Eq. (1).

$F_{\mathrm{c}}=\frac{1}{n} \sum_{i=1}^{i-n}\left(w_{i}-\bar{w}\right)\left(c_{i}-\bar{c}\right)=\overline{w^{\prime} c^{\prime}}$

In this study, $c$ corresponds to $\Sigma$ PNs, PAN, PPN, and MPAN, and $w$ represents the vertical wind speed. The primes in Eq. (1) are the deviation from the mean, the subscripts $i$ refer to individual fast time resolution measurements, and the bar indicates the mean of $\mathrm{n}$ data points over the course of a single measurement period (15-30 min).

Several filters were applied to the derived fluxes to assure they are accurate. To assess stationarity (e.g. whether a 30min flux was representative of the average surface exchange over the sampling period), each flux measurement period $(\sim 30 \mathrm{~min})$ was divided into 5 equal periods and the averaged flux of each subset, $F_{\text {sub }}$, was compared to the 30-min total flux, $F_{30 \text { min }}$. If the ratio $F_{\text {sub }} / F_{30}$ min differed from unity by more than $30 \%$ then the measurement period was determined to be non-stationary and that entire half hour was removed from the dataset (Foken and Wichura, 1996). Flux data with large tilt angles $\left(>5^{\circ}\right)$ were also rejected (Lee et al., 2004). We include only observations with frictional velocities between $0.1 \mathrm{~m} \mathrm{~s}^{-1}$ and $1.5 \mathrm{~m} \mathrm{~s}^{-1}$ (e.g. Foken and Nappo, 2008). The lower limit in this window insures that turbulence is sufficient for reliable estimates of the flux at this site (Farmer et al., 2006). Use of a lower limit of 0.05 or $0.2 \mathrm{~m} \mathrm{~s}^{-1}$ does not affect our conclusions. After the application of these criteria for reliable observations, $67 \%$ of daytime and $61 \%$ of nighttime data remained and were used to calculate the flux.

The flux of the sum of individual APNs, $F_{\mathrm{APNs}}$, is defined as the sum of the separately calculated PAN, PPN, and MPAN fluxes. We calculated the $\Sigma$ PN flux, $F_{\Sigma \text { PNs }}$, using the concentration difference between ambient $\left(\mathrm{NO}_{2}\right)$ and the $180^{\circ} \mathrm{C}\left(\mathrm{NO}_{2}+\Sigma \mathrm{PNs}\right)$ channel. Nearly identical results are obtained if we calculated the flux of $\mathrm{NO}_{2}$ and the flux of $\left(\mathrm{NO}_{2}+\Sigma \mathrm{PNs}\right)$ taking the difference to be the $\Sigma \mathrm{PN}$ flux.

We characterize the uncertainty budgets of the two instruments and the difference in concentration and flux of the two instruments as a combination of systematic and random terms. The systematic terms are ones we believe would be corrected either by application of a single multiplicative constant to the observations of each instrument or that result from imperfect correction for finite instrument response time and sensor separation. The random terms are associated with finite precision of the measurements. Many of these systematic terms are common to both instruments and thus cancel in the difference, since we show the two instruments measure nearly identical concentrations at noon. The individual elements are described in Table 2 and detailed procedure can be found elsewhere (Farmer et al., 2006; Wolfe et al., 2009; Min et al., 2012). 
Table 2. Estimated flux analysis errors.

\begin{tabular}{llllll}
\hline \multicolumn{1}{c}{ Source of Error } & Bias & $F_{\Sigma \text { PNs }}$ & $F_{\text {APNs }}$ & $F_{X P N s}$ \\
\hline & Data acquisition scheme (Dye laser line-locking) & unbiased & $<3 \%$ & - & $<3 \%$ \\
& Sensor separation \& & underestimated & $<2 \%$ & $<2 \%$ & $\sim 0 \%$ \\
\multirow{3}{*}{ Systematic Error } & High frequency damping & & & & \\
& Instrumental response time & underestimated & $<8 \%$ & $<12 \%$ & $<4 \%$ \\
& Absolute Concentration Estimation & unbiased & $<10 \%$ & $<2 \%$ & $<5 \% *$ \\
\cline { 2 - 6 } & Total Systematic Error & unbiased & $<14 \%$ & $<25 \%$ & $<7 \%$ \\
\hline & Random Noise Error** & unbiased & $<16 \%$ & $<7 \%$ & $<17.5 \%$ \\
\hline
\end{tabular}

* Determined from 1:1 concentration comparison;

** Estimated form the covariances at several lag times far from the true lag $( \pm 230-250 \mathrm{~s})$.

Briefly, the systematic uncertainty in $F_{\Sigma}$ PNs is estimated to be $<14 \%$ calculated as the square root of the sum of squares of the uncertainties in the instrument calibration $(<10 \%)$; sensor separation and inlet dampening $(<2 \%)$, instrument response time $(<8 \%)$ and line-locking cycle for the dye laser data acquisition scheme $(<3 \%)$. The systematic uncertainty in $F_{\text {APNs }}$ measured by TD-CIMS is estimated to be $<25 \%$ calculated as the square root of the sum of squares of the uncertainties in the instrument calibration $(<22 \%)$, sensor separation and inlet dampening $(<2 \%)$ and instrument response time $(<12 \%)$. The concentration calibration errors do not contribute to the systematic uncertainty in the flux difference between $F_{\Sigma}$ PNs and $F_{\text {APNs }}$. We calculate this uncertainty to be $\sim 7 \%$, taking into account the common uncertainties in $F_{\Sigma \text { PNs }}$ and $F_{\mathrm{APNs}}$ and the observation that the measured concentration differences are less than $5 \%$ (e.g Fig. 2). Fitting the measurements shown in Fig. 2 to a line and allowing the intercept to vary results in an estimate of $4.7 \%$ difference in the concentrations observed by the two instruments. The difference is $2 \%$ when the intercept is fixed at zero. Allowing the intercept to vary in the fit did not reduce the $R^{2}$. We take the $5 \%$ number to be conservative, but the $2 \%$ number would be a reasonable choice.

The random error terms in flux analysis follow counting statistics $\left(<10 \%\right.$ for $F_{\Sigma \text { PNs }}$ and $<20 \%$ for $F_{\mathrm{APNs}}$ over half hour average flux measurements) which drastically reduced with number data point averaging (followed by Farmer et al., 2006 and Wolfe et al., 2009). The total random error is estimated from the variance of the flux calculated over a range of lag times far from the true lag (Ruuskanen et al., 2011). Here we define our flux detection limit as 2 times of the standard deviation of the covariance within the time window from $\pm 230 \sim 250$ s during daytime (09:00-18:00) and find detection limits of $0.15 \mathrm{ppt} \mathrm{m} \mathrm{s}^{-1}$ for $F_{\Sigma}$ PNs and $0.19 \mathrm{ppt} \mathrm{m} \mathrm{s}{ }^{-1}$ for $F_{\mathrm{APNs}}$. Using this approach we find the random uncertainties in fluxes (Table 2 ) to be $<16 \%$ for $F_{\Sigma \text { PNs }}<7 \%$ for $F_{\mathrm{APNs}}$ and $<19 \%$ for $F_{\mathrm{XPNs}}$. Note that the larger fractional uncertainty in $F_{\Sigma}$ PNs arises from the smaller measured flux, as the absolute variability in the covariance at $\pm 230-250 \mathrm{~s}$ is smaller for the $F_{\Sigma P N}$ measurement (Fig. 3).

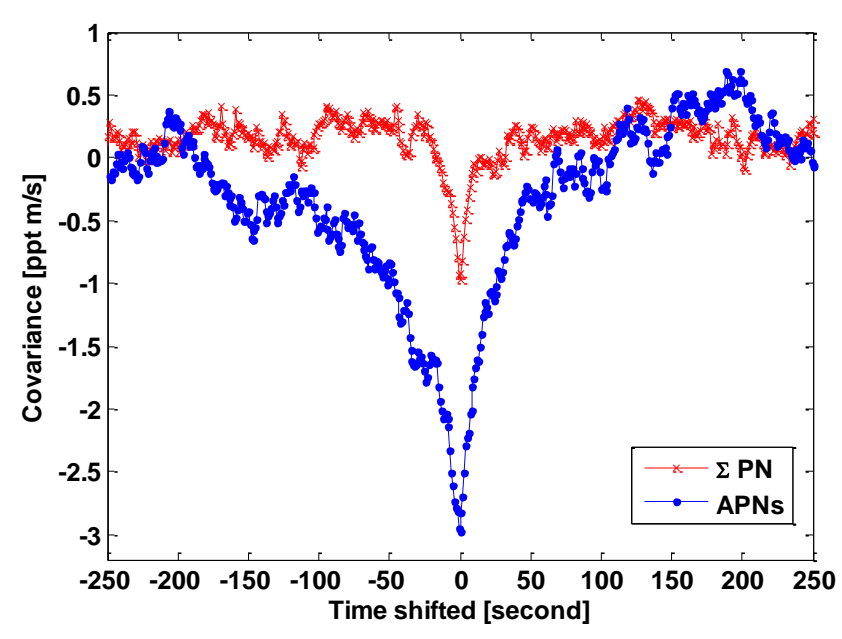

Fig. 3. Covariant plots of vertical wind speed and concentration for $\Sigma$ PNs (red crossed lines) and APNs (blue circled lines) corrected for lag time observed by TD-LIF and TD-CIMS respectively, averaged over daytime (09:00-18:00) throughout the whole campaign.

\section{Results}

As has been described previously, $\Sigma$ PN and APN abundances at the BEARPEX site reflect advection of precursors from the city of Sacramento ( $\sim 5 \mathrm{~h}$ upwind) and from the nearer-field upwind oak belt ( $\sim 3 \mathrm{~h}$ upwind) (Dillon et al., 2002; Farmer et al., 2006; Day et al., 2009; LaFranchi et al., 2009; Wolfe et al., 2009). The concentrations of all PN species increased from noon to 18:00 (PST) and high concentrations of $\Sigma$ PNs and APNs persisted past midnight (Fig. 4). Both instruments observed similar diurnal patterns at all heights

Figure 5 shows the diurnal pattern of XPNs the difference between $\Sigma$ PNs and APNs (XPNs $\equiv \Sigma$ PNs - APNs) at the different heights. At $18 \mathrm{~m}$, XPNs increase beginning at $18 \mathrm{hrs}$ to a concentration of approximately $100 \mathrm{ppt}$ and are indistinguishable from zero between 9 and $18 \mathrm{~h}$. In contrast, near the forest floor XPNs approach 100 ppt during the afternoon (15:00-18:00) when the above canopy values are at a 

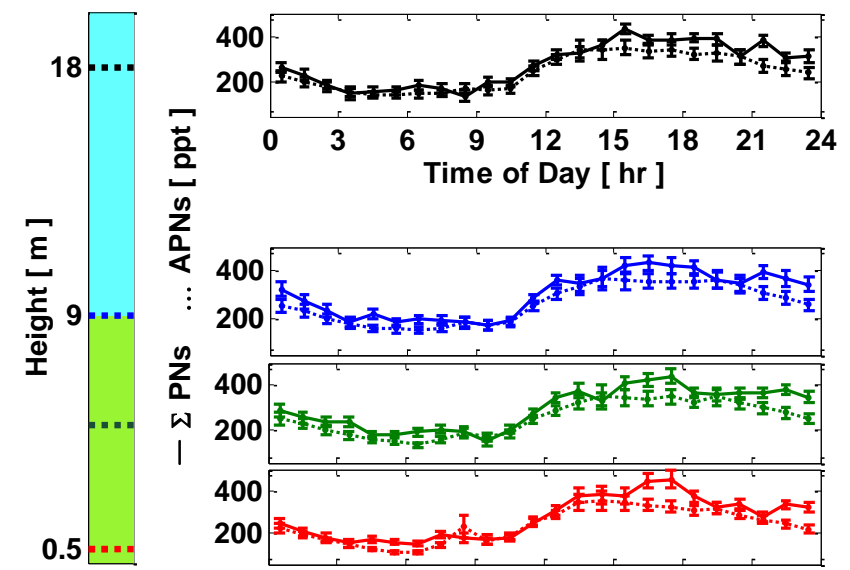

Fig. 4. Diurnal patterns of $\Sigma$ PNs (solid lines) and APNs (dashed lines) at each height. The vertical bars are the $1 \sigma$ variance divided by square root of number of data points. The left box indicates the measurement height, with green at or below the $9 \mathrm{~m}$ average canopy height and blue above that point. Dashed lines are the specific measurement heights.
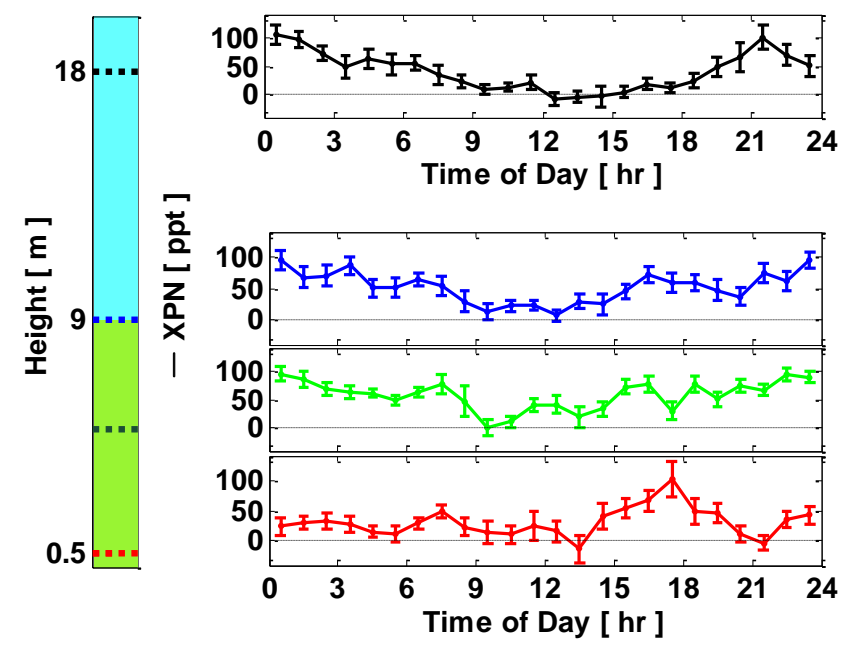

Fig. 5. Diurnal pattern of XPNs at different heights. The vertical bars represent the $1 \sigma$ variance divided by square root of number of data points in the observations. The left box indicates the measurement height, with green at or below the $9 \mathrm{~m}$ average canopy height and blue above that point. Dashed lines are the specific measurement heights.

minimum. In the middle of the canopy there is an apparent transition region. While it is theoretically possible that the $\Sigma$ PNs signal could be due to $\mathrm{N}_{2} \mathrm{O}_{5}$, we expect the contribution of $\mathrm{N}_{2} \mathrm{O}_{5}$ to the XPN is negligible since the lifetime of $\mathrm{NO}_{3}$ at this site characterized to reaction with $\mathrm{BVOC}$ is too short to sustain concentrations of $\mathrm{N}_{2} \mathrm{O}_{5}$ that are more than a fraction of a ppt.

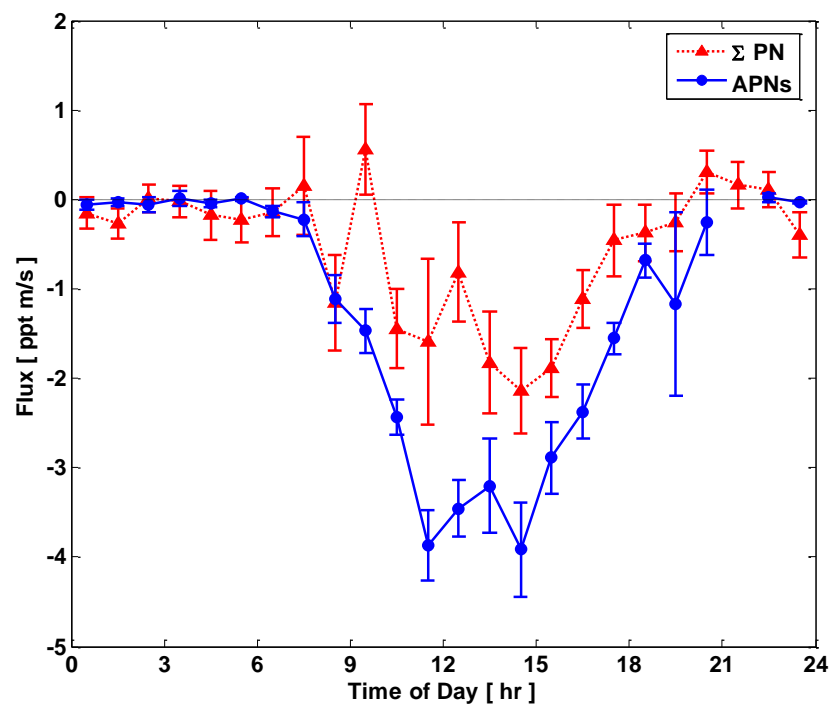

Fig. 6. Diurnal pattern of $F_{\Sigma \text { PNs }}$ and $F_{\text {APNs }}$. The vertical bars are the $1 \sigma$ variance divided by square root of number of data points. Both species exhibit a downward flux, indicating the dominance of in-canopy sinks, though PNs 30-60\% less negative than $F_{\text {APNs }}$ during daytime.

The diurnal pattern in eddy covariance $\Sigma P N$ and APN fluxes (Fig. 6) are similar in shape and direction with peak downward fluxes around $15 \mathrm{~h}$. This general pattern is similar to the APN flux observations reported by Wolfe et al. (2009) using measurements $2 \mathrm{yr}$ earlier at this same study site. Both the APN and $\Sigma$ PN measurements give fluxes that are opposite in sign to the observations of $\Sigma$ PN fluxes also made at this site during summer 2004 (Farmer et al., 2006). While the sign of the two flux measurements is the same, the magnitude of $\Sigma P N$ and APN fluxes are significantly different. We observe a 30-60\% slower downward flux of $\Sigma$ PNs than of APNs with a maximum difference during the daytime (09:00-18:00). This is surprising given the concentrations at $18 \mathrm{~m}$, the height where we observed fluxes, are identical to within $2-5 \%$.

Two pieces of information provide hints about the source of the flux difference. For convenience we define $\Delta \mathrm{c}$ to be the mixing ratio difference of species $c$ from $18 \mathrm{~m}$ to height $i$, as:

$\Delta c=c_{i}-c_{18 \mathrm{~m}}$

Positive values of $\Delta c$ indicate enhancements in species $c$ at height $i$ relative to $18 \mathrm{~m}$ while negative values of $\Delta \mathrm{c}$ indicate a depletion of $c$ at height $i$ relative to $18 \mathrm{~m}$. Figure 7 shows the vertical gradients $(\Delta c)$ of $\Sigma$ PNs and XPNs at five different times of day. During the daytime, $\Sigma$ PNs and XPNs are larger within the canopy than above. At night, values of both observables are much lower near the forest floor than above the canopy indicating loss rates of $\Sigma$ PNs or XPN are faster than the production rates. These profiles are suggestive 


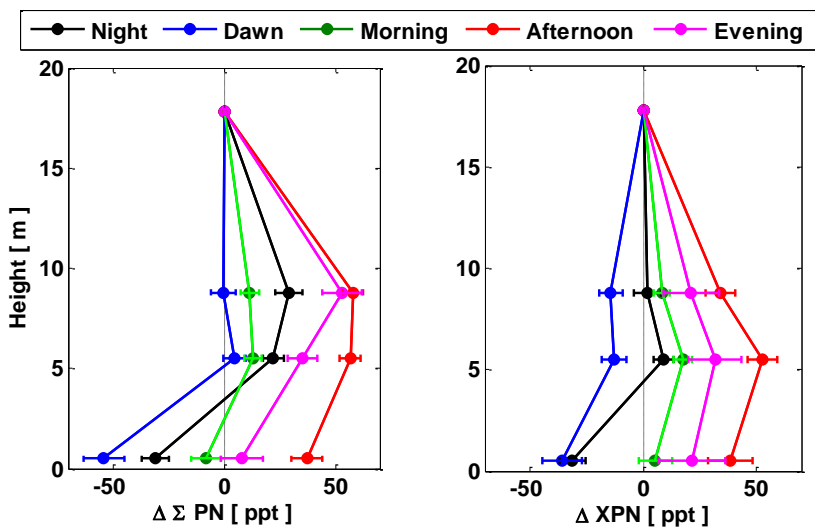

Fig. 7. Diurnal pattern of vertical mixing ratio differences of $\Sigma$ PNs (left) and XPNs (right) with respect to the $18 \mathrm{~m}$ mixing ratios. The horizontal bars are the $1 \sigma$ variance divided by square root of number of data points. Positive values of $\Delta \Sigma P N$ and $\Delta X P N$ indicate enhanced concentrations and negative values represent depleted concentration compared to $18 \mathrm{~m}$. Colors represent the time of day black (21:00-03:00), blue (03:00-06:00), green (06:00-12:00), red (12:00-18:00) and magenta (18:00-21:00).

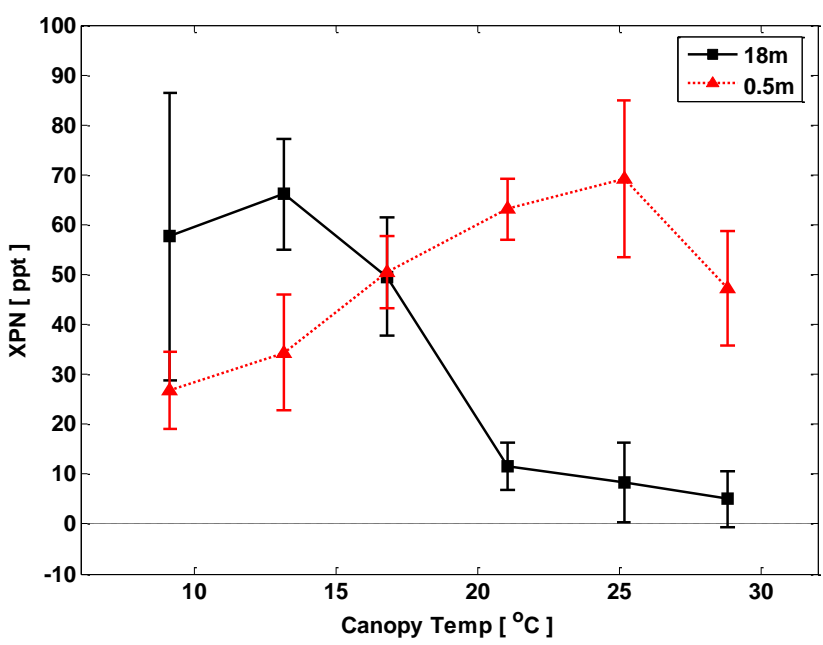

Fig. 8. Temperature dependence of XPNs at 0.5 and $18 \mathrm{~m}$ during mornings (06:00-12:00). The vertical bars represent the $1 \sigma$ variance divided by square root of number of data points.

of a daytime source of XPNs within the canopy. This source would lead to a net upward flux of XPNs, consistent with the observed difference between APN and $\Sigma$ PNs fluxes.

A second piece of evidence indicating a within canopy source of XPNs is the temperature dependence of the XPN concentration at different heights. Figure 8 shows observations of the temperature dependence in the morning period (06:00-12:00), when large flux differences were observed alongside relatively shallow gradients. During this time period XPNs at $18 \mathrm{~m}$ decrease with increasing temperature while at the forest floor $(0.5 \mathrm{~m})$ XPNs increase with temperature. XPNs at $5 \mathrm{~m}$ and $9 \mathrm{~m}$ (not shown here) are intermediate between these two features. The temperature dependence of XPN at each height indicates that the production process is stronger within the canopy - due to elevated concentrations of biogenic hydrocarbons and/or soil-emitted $\mathrm{NO}_{\mathrm{x}}$ - and that XPN loss processes dominate above the canopy. Although we chose this time interval to map directly to the time window shown in Fig. 7, we arrive at the same conclusions if we use a narrower time window such as 06:00-09:00 or 09:0012:00.

\section{Discussion}

We have also investigated a variety of possible issues with our instrumentation, finding no source of error able to explain both the flux and gradient differences. The largest of these potential sources was pointed out in a recent study by Phillips and co-workers (2012) who found that peroxyacetic acid (PAA: $\mathrm{CH}_{3} \mathrm{C}(\mathrm{O}) \mathrm{OOH}$ ) is a potential interference to TD-CIMS measurements of PAN with $\mathrm{I}^{-}$detection. The suggestion they made was that a large background in the TD-CIMS instrument could contribute to the observed flux without contributing to an observed concentration difference. During BEARPEX 2009, we do observe a diurnally varying background in the TD-CIMS measurements of PAN (Fig. 9). If we assume that this signal of about 25 ppt PANequivalent at noon is entirely due to PAA and that PAA deposits at the turbulence limit of $2-4 \mathrm{~cm} \mathrm{~s}^{-1}$, then we calculate a PAA flux of $0.25-1 \mathrm{ppt} \mathrm{m} \mathrm{s}^{-1}$. This value is $10-40 \%$ of the flux we have attributed to an unidentified PAN-like molecule. Although a flux of this background, whatever the molecule, might be important, we emphasize that the gradient of the background and of the concentration of XPNs is the reverse of what would be expected for a species with a downward flux. Both are higher within the canopy than above. If the background has a normal flux-gradient relationship, then its flux will be upward and would have the effect of reducing the downward flux of PAN. If this is the case, then the XPN flux would be even higher than derived here.

This leads us to believe that there is an upward flux of one or more peroxynitrates that are not measured by the TDCIMS.

Other evidence supporting this suggestion is indicated by the temperature and PAR dependence of the XPN fluxes and exchange velocities, Vex, (Fig. 10). We define the flux and Vex of XPNs as in Eq. (3):

$F_{\mathrm{XPNs}}=F_{\Sigma \mathrm{PNs}}-F_{\mathrm{APNs}}$ and $V \operatorname{ex}_{\mathrm{XPNs}}=\frac{F_{\mathrm{XPNs}}}{[\mathrm{XPN}]}$

$F_{\mathrm{XPNs}}$ and Vex $\mathrm{XPNs}$ are independent of canopy temperature below $20^{\circ} \mathrm{C}$ and then increase steeply with increasing temperature. $F_{X P N s}$ and Vex XPNs increase with PAR to 1200 $\mu \mathrm{mol} / \mathrm{m}^{2} / \mathrm{s}$ then decrease. These features are similar to previously reported behavior for BVOCs at this site (Lee et al., 2005; Holzinger et al., 2005; Schade and Goldstein, 2001). 

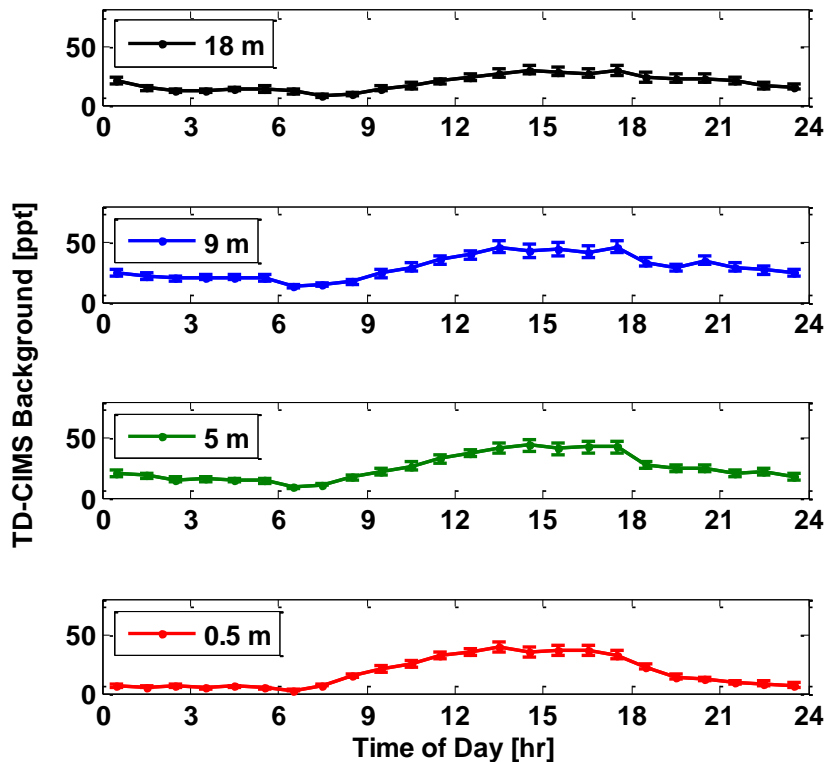

Fig. 9. Diurnal patterns of TD-CIMS background converted to PAN-equivalent concentration. The vertical bars represent the $1 \sigma$ variance divided by square root of number of data points in the observations.
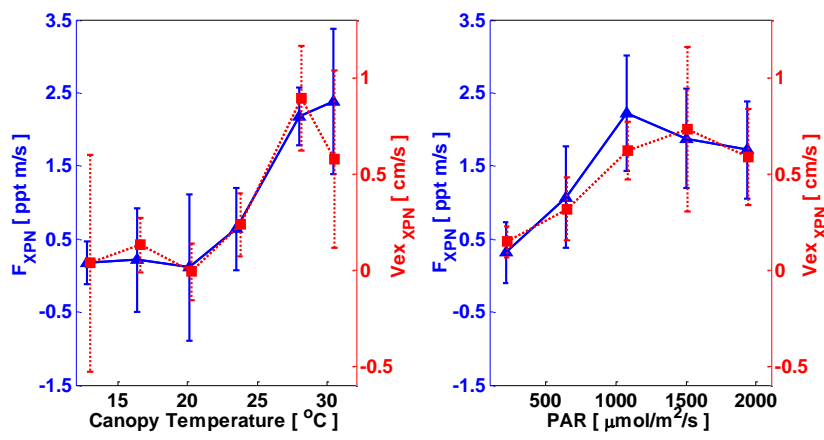

Fig. 10. Canopy temperature (left) and PAR (right) dependence of $F_{\mathrm{XPNs}}$ and Vex XPNs. The vertical bars are the $1 \sigma$ variance divided by square root of number of data points.

We can estimate the source strength needed to produce the observed XPN flux by assuming steady-state XPN chemical production and XPN flux out of the canopy:

$F_{\mathrm{XPNs}} \approx F_{\mathrm{P}-\mathrm{XPNs}}$.

Here, $F_{\mathrm{P}-\mathrm{XPNs}}$ is the net chemical production of XPNs. Other terms in the flux budget including thermochemical loss, plant uptake, and canopy storage are calculated to be more than a factor of 10 smaller and can be neglected. The flux of XPNs, during daytime $\left(2.3 \pm 0.4 \mathrm{ppt} \mathrm{m} \mathrm{s}^{-1}\right.$ : mean $\pm 1 \sigma$ divided by square root of number of data points) is then approximately the integral of chemical production within the canopy. To calculate the chemical production rate, we assume the canopy integrated chemical production of $2.3 \mathrm{ppt} \mathrm{m} \mathrm{s}^{-1}$ occurs uniformly from the forest floor to the
$18 \mathrm{~m}$ measurement height (Eq. 5). The PA radical concentration needed to support the observed flux of XPNs is calculated by solving Eqs. (5) and (6) for $\mathrm{XO}_{2}$ using an average daytime concentration of $\mathrm{NO}_{2}$ of $250 \mathrm{ppt}$ and a rate constant for $k_{\mathrm{XO}_{2}+\mathrm{NO}_{2}}$ of $1.1 \times 10^{-11} \mathrm{~cm}^{3} \mathrm{molec}^{-1} \mathrm{~s}^{-1}$, chosen in analogy to the rate for PAN formation at $298 \mathrm{~K}$ and 868 mbar (Tyndall et al., 2001):

$$
\begin{aligned}
& F_{\mathrm{P}-\mathrm{XPNs}}=\int_{z 0}^{z}\left(P_{\mathrm{XPNs}}\right) d z=2.3( \pm 0.4) \mathrm{pptm} \mathrm{s}^{-1} \\
& P_{\mathrm{XPNs}}=k_{\mathrm{XO}_{2}+\mathrm{NO}_{2}}\left[\mathrm{XO}_{2}\right]\left[\mathrm{NO}_{2}\right]
\end{aligned}
$$

Solving for $\mathrm{XO}_{2}$, we find a concentration of $2.3 \pm 0.7 \mathrm{ppt}$. This is about $10 \%$ of the average daytime $\mathrm{HO}_{2}$ observed at the site (22 \pm 11 ppt) (Mao et al., 2012). One plausible candidate for BVOC inducing XPN formation is sesquiterpene (SQT) oxidation. The observed sesquiterpene concentration within canopy at this site is approximately $85 \mathrm{ppt}$ during daytime. Using $\beta$-caryophyllene as an example, the $\mathrm{OH}$ and $\mathrm{O}_{3}$ reaction rate constants are $1.97 \times 10^{-11} \mathrm{~cm}^{3}$ molec $^{-1} \mathrm{~s}^{-1}$ and $1.16 \times 10^{-14} \mathrm{~cm}^{3} \mathrm{molec}^{-1} \mathrm{~s}^{-1}$, respectively (Shu and Atkinson, 1994; Shu and Atkinson, 1995). The typical concentrations of $\mathrm{OH}$ and $\mathrm{O}_{3}$ within the canopy during BEARPEX 2009 were 0.16ppt and $54 \mathrm{ppb}$. For a 100-s canopy mixing timescale (Wolfe et al., 2009), we calculate $198 \mathrm{ppt}$ of oxygenated BVOC (oBVOC) produced during SQT oxidation within the canopy. The source of $\mathrm{XO}_{2}$ can be estimated considering the reaction of this oBVOC with $\mathrm{OH}$ radical, Eq. (7).

$$
\frac{d\left[\mathrm{XO}_{2}\right]}{d t}=k_{\mathrm{oBVOC}+\mathrm{OH}}[\mathrm{oBVOC}][\mathrm{OH}]
$$

Solving for the rate constant to form an $\mathrm{XO}_{2}$ radical using this estimate of oBVOC and the observed $\mathrm{OH}$ we find a rate constant of $2.3 \times 10^{-11} \mathrm{~cm}^{3} \mathrm{molec}^{-1} \mathrm{~s}^{-1}$ which is in the range of typical rate constants for the reaction of $\mathrm{OH}$ with aldehydes, confirming the plausibility of a sesquiterpene source of XPNs.

In addition to the reasonable value for the inferred rate constant there is laboratory and computational evidence supporting the idea that BVOC emitted by forest canopies can result in upward fluxes of PNs. For example, in a recent chamber study PNs built on a more complex organic framework than the three APNs observed in our study were observed during $\beta$-caryophyllene ozonolysis (Jenkin et al., 2012). Several other studies have discussed production of PNs built on a larger carbon backbone, including $\alpha$-pinene (Noziere and Barnes, 1998), $d$-limonene (Leungsakul et al., 2005) and nonanal (Bowman et al., 2003) derived PNs. Using a canopy box model, Wolfe et al (2011) found upward fluxes of a PN derived from 2-methyl-3-buten-2-ol oxidation. This molecule likely cannot be the entire source of our upward flux as that particular product is not efficiently formed (Carrasco et al., 2006), however the calculations show that several 
such PN products form and are transported out of the canopy on the relevant time scales.

\section{Implications of XPNs formation}

The formation of XPNs within the canopy suggests a complex array of effects on PN fluxes and, more broadly, reactive nitrogen forest-atmosphere exchange. The first consequence is that the sign of the total PN flux depends on the relative magnitude of the upward flux of XPN and downward fluxes of PAN, PPN and MPAN. This offers one possible explanation for the upward $\Sigma$ PN flux previously observed at this site (Farmer et al., 2006). If this is the case, in the Farmer et al. measurements, the upward flux of XPNs was a consequence of vegetation acting as a source of PN precursors rather than, as is often assumed, a sink through stomatal uptake. Explaining both data sets requires the biogenic source of PN precursors at the BEARPEX site to have decreased over the last decade. The large decrease in $\mathrm{NO}_{\mathrm{x}}(\sim 67 \%$ from 2001-2009) and NOy ( 30\%) concentration over this time interval, imply a corresponding decrease in $\mathrm{OH}$ (e.g. Murphy et al., 2006; La Franchi et al., 2011). Since PAN precursors are largely secondary products of $\mathrm{OH}$ reactions with BVOC, it is reasonable to assume they have decreased over time. In addition, high $\mathrm{O}_{3}$ levels have also decreased, a sign of slower oxidative chemistry and reducing the role of ozone as an oxidant of alkenes (LaFranchi et al., 2011).

A second implication is the possible role of XPNs in explaining poorly understood canopy reduction factors for soil $\mathrm{NO}_{\mathrm{x}}$ emissions. XPN formation affects the total $\mathrm{N}$ flux, as upward fluxes of XPNs function to transfer within canopy $\mathrm{NO}_{2}$ to the $\Sigma$ PN pool. XPN formation is a plausible within canopy $\mathrm{NO}_{\mathrm{x}}$ loss process and is consistent with the long standing discussion about missing $\mathrm{NO}_{\mathrm{x}}$ sinks within canopies, which are parameterized as a canopy reduction factors and widely invoked in global models. These models otherwise find the strength of soil $\mathrm{NO}_{\mathrm{x}}$ emissions lead to dramatic overestimates of $\mathrm{O}_{3}$ (e.g. Jacob and Wofsy, 1990). Deposition to vegetation is the most studied $\mathrm{NO}_{\mathrm{x}}$ sink process. However, the role of vegetation with respect to the $\mathrm{NO}_{\mathrm{x}}$ flux is still controversial (Lerdau et al., 2000). Here, we suggest that XPN formation is one possible mechanism of $\mathrm{NO}_{\mathrm{x}}$ loss within the canopy.

\section{Conclusions}

We observed a significant (30-60\%) difference between the deposition rate of $\Sigma$ PNs, and that of the sum of three speciated PNs. The difference in these fluxes suggests formation within the canopy of PNs other than PAN, PPN and MPAN. The time of day and temperature dependence of the vertical gradient of XPNs also supports this idea. We show the flux of XPN must be upward, indicating the possibility that local vegetation acts indirectly as a source of PN rather than as a passive PN sink, a mechanism that can explain the upward $\Sigma$ PN flux reported by Farmer et al. (2006). In this mechanism, oxidation of biogenic VOC may affect not only the magnitude of $\mathrm{PN}$ fluxes, but also $\mathrm{NO}_{\mathrm{x}}$ fluxes, supporting the ideas of a strong connection between turbulent transport and chemical processes in biosphere-atmosphere exchange, as proposed by Wolfe et al. (2009 and 2011) and Farmer et al. (2006), and offering at least a partial explanation for canopy reduction factors.

Acknowledgements. This research was supported by the National Science Foundation (grants NSF-AGS 1120076, ATM-0639847, and ATM-0633897). We thank Sierra Pacific Industries for use of their land, and the University of California, Berkeley, Blodgett Forest Research Station for cooperation in facilitating this research. We also thank to Dennis D. Baldocchi for helpful comments on EC flux. GMW acknowledges support from US-EPA STAR Fellowship (Agreement No. FP-91698901). This work has not been formally reviewed by EPA or NSF.

Edited by: A. B. Guenther

\section{References}

Bianco, L., Djalalova, I. V., King, C. W., and Wilczak, J. M.: Diurnal Evolution and Annual Variability of Boundary-Layer Height and Its Correlation to Other Meteorological Variables in California's Central Valley, Bound.-Lay. Meteorol., 140, 491-511, doi:10.1007/s10546-011-9622-4, 2011.

Bowman, J. H., Barket, D. J., and Shepson, P. B.: Atmospheric chemistry of nonanal, Environ. Sci. Technol., 37, 2218-2225, doi:10.1021/Es026220p, 2003.

Bytnerowicz, A. and Fenn, M. E.: Nitrogen deposition in California forests: A review, Environ. Pollut., 92, 127-146, 1996.

Cahill, T. M., Seaman, V. Y., Charles, M. J., Holzinger, R., and Goldstein, A. H.: Secondary organic aerosols formed from oxidation of biogenic volatile organic compounds in the Sierra Nevada Mountains of California, J. Geophys. Res., 111, D16312, doi:10.1029/2006jd007178, 2006.

Carrasco, N., Doussin, J. F., Picquet-Varrault, B., and Carlier, P.: Tropospheric degradation of 2-hydroxy-2-methylpropanal, a photo-oxidation product of 2-methyl-3-buten-2-ol: Kinetic and mechanistic study of its photolysis and its reaction with $\mathrm{OH}$ radicals, Atmos. Environ., 40, 2011-2019, doi:10.1016/j.atmosenv.2005.11.042, 2006.

Choi, W., Faloona, I. C., McKay, M., Goldstein, A. H., and Baker, B.: Estimating the atmospheric boundary layer height over sloped, forested terrain from surface spectral analysis during BEARPEX, Atmos. Chem. Phys., 11, 6837-6853, doi:10.5194/acp-11-6837-2011, 2011.

Cohen, R. C., Goldstein, A. H., and the BERPEX Science team: The Biosphere Effects on Aerosol and Photochemistry EXperiment (BEARPEX), Atmos. Chem. Phys. Discuss., in preparation, 2012.

Day, D. A., Wooldridge, P. J., Dillon, M. B., Thornton, J. A., and Cohen, R. C.: A thermal dissociation laser-induced fluorescence instrument for in situ detection of $\mathrm{NO}_{2}$, peroxy ni- 
trates, alkyl nitrates, and $\mathrm{HNO}_{3}$, J. Geophys. Res., 107, 4045, doi:10.1029/2001jd000779, 2002.

Day, D. A., Farmer, D. K., Goldstein, A. H., Wooldridge, P. J., Minejima, C., and Cohen, R. C.: Observations of $\mathrm{NO}_{\mathrm{x}}, \Sigma \mathrm{PNs}$, $\Sigma$ ANs, and $\mathrm{HNO}_{3}$ at a Rural Site in the California Sierra Nevada Mountains: summertime diurnal cycles, Atmos. Chem. Phys., 9, 4879-4896, doi:10.5194/acp-9-4879-2009, 2009.

Dillon, M. B., Lamanna, M. S., Schade, G. W., Goldstein, A. H., and Cohen, R. C.: Chemical evolution of the Sacramento urban plume: Transport and oxidation, J. Geophys. Res., 107, D10310, doi:10.1029/2001jd000969, 2002.

Doskey, P. V., Kotamarthi, V. R., Fukui, Y., Cook, D. R., Breitbeil, F. W., and Wesely, M. L.: Air-surface exchange of peroxyacetyl nitrate at a grassland site, J. Geophys. Res., 109, D23S10, doi:10.1029/2004jd004533, 2004.

Farmer, D. K., Wooldridge, P. J., and Cohen, R. C.: Application of thermal-dissociation laser induced fluorescence (TD-LIF) to measurement of $\mathrm{HNO}_{3}$, Lalkyl nitrates, $\Sigma$ peroxy nitrates, and $\mathrm{NO}_{2}$ fluxes using eddy covariance, Atmos. Chem. Phys., 6, 3471-3486, doi:10.5194/acp-6-3471-2006, 2006.

Fiore, A. M., Levy, H., and Jaffe, D. A.: North American isoprene influence on intercontinental ozone pollution, Atmos. Chem. Phys., 11, 1697-1710, doi:10.5194/acp-11-1697-2011, 2011.

Foken, T., and Wichura, B.: Tools for quality assessment of surfacebased flux measurements, Agr. Forest. Meteorol., 78, 83-105, 1996.

Foken, T. and Nappo, C. J.: Micrometeorology, Springer, Berlin, Germany, 61-104, 2008.

Goulding, K. W. T., Bailey, N. J., Bradbury, N. J., Hargreaves, P., Howe, M., Murphy, D. V., Poulton, P. R., and Willison, T. W.: Nitrogen deposition and its contribution to nitrogen cycling and associated soil processes, New. Phytol., 139, 49-58, 1998.

Holland, E. A., Braswell, B. H., Lamarque, J. F., Townsend, A., Sulzman, J., Muller, J. F., Dentener, F., Brasseur, G., Levy, H., Penner, J. E., and Roelofs, G. J.: Variations in the predicted spatial distribution of atmospheric nitrogen deposition and their impact on carbon uptake by terrestrial ecosystems, J. Geophys. Res., 102, 15849-15866, 1997.

Holzinger, R., Lee, A., Paw, K. T., and Goldstein, A. H.: Observations of oxidation products above a forest imply biogenic emissions of very reactive compounds, Atmos. Chem. Phys., 5, 6775, doi:10.5194/acp-5-67-2005, 2005.

Hudman, R. C., Jacob, D. J., Cooper, O. R., Evans, M. J., Heald, C. L., Park, R. J., Fehsenfeld, F., Flocke, F., Holloway, J., Hubler, G., Kita, K., Koike, M., Kondo, Y., Neuman, A., Nowak, J., Oltmans, S., Parrish, D., Roberts, J. M., and Ryerson, T.: Ozone production in transpacific Asian pollution plumes and implications for ozone air quality in California, J. Geophys. Res., 109, 2189, doi:10.1029/2004jd004974, 2004.

Jacob, D. J. and Wofsy, S. C.: Budgets of Reactive Nitrogen, Hydrocarbons, and Ozone over the Amazon-Forest during the Wet Season, J. Geophys. Res., 95, 16737-16754, 1990.

Jenkin, M. E., Wyche, K. P., Evans, C. J., Carr, T., Monks, P. S., Alfarra, M. R., Barley, M. H., McFiggans, G. B., Young, J. C., and Rickard, A. R.: Development and chamber evaluation of the MCM v3.2 degradation scheme for $\beta$-caryophyllene, Atmos. Chem. Phys., 12, 5275-5308, doi:10.5194/acp-12-52752012, 2012.
LaFranchi, B. W., Wolfe, G. M., Thornton, J. A., Harrold, S. A., Browne, E. C., Min, K. E., Wooldridge, P. J., Gilman, J. B., Kuster, W. C., Goldan, P. D., de Gouw, J. A., Mckay, M., Goldstein, A. H., Ren, X., Mao, J., and Cohen, R. C.: Closing the peroxy acetyl nitrate budget: observations of acyl peroxy nitrates (PAN, PPN, and MPAN) during BEARPEX 2007, Atmos. Chem. Phys., 9, 7623-7641, doi:10.5194/acp-9-7623-2009, 2009.

LaFranchi, B. W., Goldstein, A. H., and Cohen, R. C.: Observations of the temperature dependent response of ozone to $\mathrm{NO}_{\mathrm{x}}$ reductions in the Sacramento, CA urban plume, Atmos Chem Phys, 11, 6945-6960, doi:10.5194/acp-11-6945-2011, 2011.

Lee, A., Schade, G. W., Holzinger, R., and Goldstein, A. H.: A comparison of new measurements of total monoterpene flux with improved measurements of speciated monoterpene flux, Atmos. Chem. Phys., 5, 505-513, doi:10.5194/acp-5-505-2005, 2005.

Lee, X., Massman, W., and Law, B.: Handbook of Micrometeorology: A Guide for Surface Flux Measurement and Analysis, Kluwer Academic Publishers, Dordrecht, The Netherlands, 2004.

Lerdau, M. T., Munger, L. J., and Jacob, D. J.: Atmospheric chemistry -The $\mathrm{NO}_{2}$ flux conundrum, Science, 289, 2291-2293, 2000.

Leungsakul, S., Jeffries, H. E., and Kamens, R. M.: A kinetic mechanism for predicting secondary aerosol formation from the reactions of d-limonene in the presence of oxides of nitrogen and natural sunlight, Atmos. Environ., 39, 7063-7082, 2005.

Mao, J., Ren, X., Zhang, L., Van Duin, D. M., Cohen, R. C., Park, J.H., Goldstein, A. H., Paulot, F., Beaver, M. R., Crounse, J. D., Wennberg, P. O., DiGangi, J. P., Henry, S. B., Keutsch, F. N., Park, C., Schade, G. W., Wolfe, G. M., Thornton, J. A., and Brune, W. H.: Insights into hydroxyl measurements and atmospheric oxidation in a California forest, Atmos. Chem. Phys., 12, 8009-8020, doi:10.5194/acp-12-8009-2012, 2012

Min, K.-E., LaFranchi, B.W., Pusede, S. E., Browne, E. C., Wooldridge, P. J., and Cohen, R., C.: Eddy-covariance measurement of $\mathrm{NO}$ and $\mathrm{NO}_{2}$ fluxes over a ponderosa pine ecosystem, Atmos. Chem. Phys. Discuss., in preparation, 2012.

Murphy, J. G., Day, D. A., Cleary, P. A., Wooldridge, P. J., Millet, D. B., Goldstein, A. H., and Cohen, R. C.: The weekend effect within and downwind of Sacramento - Part 1: Observations of ozone, nitrogen oxides, and VOC reactivity, Atmos. Chem. Phys., 7, 5327-5339, doi:10.5194/acp-7-5327-2007, 2007

Noziere, B. and Barnes, I.: Evidence for formation of a PAN analogue of pinonic structure and investigation of its thermal stability, J. Geophys. Res., 103, 25587-25597, 1998.

Oka, E., Tagami, Y., Oohashi, T., and Kondo, N.: A physiological and morphological study on the injury caused by exposure to the air pollutant, peroxyacetyl nitrate (PAN), based on the quantitative assessment of the injury, J. Plant. Res., 117, 27-36, doi:10.1007/s10265-003-0127-1, 2004.

Okano, K., Tobe, K., and Furukawa, A.: Foliar Uptake of Peroxyacetyl Nitrate (PAN) by Herbaceous Species Varying in Susceptibility to this Pollutant, New. Phytol., 114, 139-145, 1990.

Ordin, L., Garber, M. J., Kindinge.Ji, Whitmore, S. A., Greve, L. C., and Taylor, O. C.: Effect of Peroxyacetyl Nitrate (PAN) in-Vivo on Tobacco Leaf Polysaccharide Synthetic Pathways Enzymes, Environ. Sci. Technol., 5, 621-626, 1971.

Parrish, D. D., Millet, D. B., and Goldstein, A. H.: Increasing ozone in marine boundary layer inflow at the west coasts of North America and Europe, Atmos. Chem. Phys., 9, 1303-1323, 
doi:10.5194/acp-9-1303-2009, 2009.

Phillips, G. J., Pouvesle, N., Thieser, J., Schuster, G., Axinte, R., Fischer, H., Williams, J., Lelieveld, J., Crowley, J. N.: Peroxyacetyl Nitrate (PAN) and peroxyacetic acid (PAA) measurements by iodide chemical ionisation mass spectrometry: first analysis of results in the boreal forest and implication for the measurement of PAN fluxes, Atmos. Chem. Phys. Discuss., 12, 20181-20207, doi:10.5194/acpd-12-20181-2012, 2012.

Russell, A. R., Valin, L. C., Bucsela, E. J., Wenig, M. O., and Cohen, R. C.: Space-based Constraints on Spatial and Temporal Patterns of $\mathrm{NO}_{\mathrm{x}}$ Emissions in California, 2005-2008, Environ Sci Technol, 44, 3608-3615, doi:10.1021/Es903451j, 2010.

Schade, G. W. and Goldstein, A. H.: Fluxes of oxygenated volatile organic compounds from a ponderosa pine plantation, J. Geophys. Res., 106, 3111-3123, 2001.

Shu, Y. G. and Atkinson, R.: Rate Constants for the Gas-Phase Reactions of $\mathrm{O}_{3}$ with a Series of Terpenes and $\mathrm{OH}$ Radical Formation from the $\mathrm{O}_{3}$ Reactions with Sesquiterpenes at $296 \pm 2 \mathrm{~K}$, Int. J. Chem. Kinet., 26, 1193-1205, 1994.

Shu, Y. H. and Atkinson, R.: Atmospheric Lifetimes and Fates of a Series of Sesquiterpenes, J. Geophys. Res., 100, 7275-7281, 1995.

Sparks, J. P., Roberts, J. M., and Monson, R. K.: The uptake of gaseous organic nitrogen by leaves: A significant global nitrogen transfer process, Geophys. Res. Lett., 30, 2189, doi:10.1029/2003GL018578, 2003.

Sparks, J. P.: Ecological ramifications of the direct foliar uptake of nitrogen, Oecologia, 159, 1-13, 2009.

Taylor, O. C.: Importance of peroxyacetylnitrate (PAN) as a phytotoxic air pollutant, J. Air Pollut., 19, 347-351, 1969.

Teklemariam, T. A. and Sparks, J. P.: Gaseous fluxes of peroxyacetyl nitrate (PAN) into plant leaves, Plant. Cell. Environ., 27, 1149-1158, 2004.

Thornton, J. A., Wooldridge, P. J., and Cohen, R. C.: Atmospheric $\mathrm{NO}_{2}$ : In situ laser-induced fluorescence detection at parts per trillion mixing ratios, Anal. Chem., 72, 528-539, 2000.

Townsend, A. R., Braswell, B. H., Holland, E. A., and Penner, J. E.: Spatial and temporal patterns in terrestrial carbon storage due to deposition of fossil fuel nitrogen, Ecol. Appl., 6, 806-814, 1996.

Turnipseed, A. A., Huey, L. G., Nemitz, E., Stickel, R., Higgs, J., Tanner, D. J., Slusher, D. L., Sparks, J. P., Flocke, F., and Guenther, A.: Eddy covariance fluxes of peroxyacetyl nitrates (PANs) and $\mathrm{NO}_{\mathrm{y}}$ to a coniferous forest, J. Geophys. Res., 111, 10.1029/2003GL018578, doi:10.1029/2005jd006631, 2006.
Tyndall, G. S., Cox, R. A., Granier, C., Lesclaux, R., Moortgat, G. K., Pilling, M. J., Ravishankara, A. R., and Wallington, T. J.: Atmospheric chemistry of small organic peroxy radicals, J. Geophys. Res., 106, 12157-12182, 2001.

Ruuskanen, T. M., Muller, M., Schnitzhofer, R., Karl, T., Graus, M., Bamberger, I., Hortnagl, L., Brilli, F., Wohlfahrt, G., and Hansel, A.: Eddy covariance VOC emission and deposition fluxes above grassland using PTR-TOF, Atmos. Chem. Phys., 11, 611-625, doi:10.5194/acp-11-611-2011, 2011.

Wolfe, G. M., Thornton, J. A., Yatavelli, R. L. N., Mckay, M., Goldstein, A. H., LaFranchi, B., Min, K. E., and Cohen, R. C.: Eddy covariance fluxes of acyl peroxy nitrates (PAN, PPN and MPAN) above a Ponderosa pine forest, Atmos. Chem. Phys., 9, 615-634, doi:10.5194/acp-9-615-2009, 2009.

Wolfe, G. M., Thornton, J. A., Bouvier-Brown, N. C., Goldstein, A. H., Park, J. H., Mckay, M., Matross, D. M., Mao, J., Brune, W. H., LaFranchi, B. W., Browne, E. C., Min, K. E., Wooldridge, P. J., Cohen, R. C., Crounse, J. D., Faloona, I. C., Gilman, J. B., Kuster, W. C., de Gouw, J. A., Huisman, A., and Keutsch, F. N.: The Chemistry of Atmosphere-Forest Exchange (CAFE) Model - Part 2: Application to BEARPEX-2007 observations, Atmos. Chem. Phys., 11, 1269-1294, doi:10.5194/acp-11-12692011, 2011.

Wooldridge, P. J., Perring, A. E., Bertram, T. H., Flocke, F. M., Roberts, J. M., Singh, H. B., Huey, L. G., Thornton, J. A., Wolfe, G. M., Murphy, J. G., Fry, J. L., Rollins, A. W., LaFranchi, B. W., and Cohen, R. C.: Total Peroxy Nitrates ( $\Sigma$ PNs) in the atmosphere: the Thermal Dissociation-Laser Induced Fluorescence (TD-LIF) technique and comparisons to speciated PAN measurements, Atmos. Meas. Tech., 3, 593-607, doi:10.5194/amt-3-5932010, 2010.

Zhang, L., Jacob, D. J., Boersma, K. F., Jaffe, D. A., Olson, J. R., Bowman, K. W., Worden, J. R., Thompson, A. M., Avery, M. A., Cohen, R. C., Dibb, J. E., Flock, F. M., Fuelberg, H. E., Huey, L. G., McMillan, W. W., Singh, H. B., and Weinheimer, A. J.: Transpacific transport of ozone pollution and the effect of recent Asian emission increases on air quality in North America: an integrated analysis using satellite, aircraft, ozonesonde, and surface observations, Atmos. Chem. Phys., 8, 6117-6136, doi:10.5194/acp-8-6117-2008, 2008. 